\title{
Quorum Sensing Regulates Exopolysaccharide Production, Motility, and Virulence in Pseudomonas syringae
}

\author{
Beatriz Quiñones, Glenn Dulla, and Steven E. Lindow \\ Department of Plant and Microbial Biology, University of California, Berkeley 94720-3102, U.S.A.
}

Submitted 27 December 2004. Accepted 1 March 2005.

\begin{abstract}
The $N$-acyl homoserine lactone (AHL)-mediated quorumsensing system in the phytopathogen Pseudomonas syringae pv. syringae requires the AHL synthase AhlI and the regulator $A h I R$, and is additionally subject to regulation by AefR. The contribution of quorum sensing to the expression of a variety of traits expected to be involved in epiphytic fitness and virulence of $P$. syringae were examined. Both an $a e f R^{-}$mutant and an $\mathrm{ahlI}^{-} \mathrm{ahlR}^{-}$double mutant, deficient in AHL production, were significantly impaired in alginate production and had an increased susceptibility to hydrogen peroxide compared with the wild-type strain. These mutants were hypermotile in culture, invaded leaves more rapidly, and caused an increased incidence of brown spot lesions on bean leaves after a 48 -h moist incubation. Interestingly, an $a e f R^{-}$mutant was both the most motile and virulent. Like the wild-type strain, the AHL-deficient mutant strains incited water-soaked lesions on bean pods. However, lesions caused by an $a h l I^{-} a h l R^{-}$double mutant were larger, whereas those incited by an $a e f R^{-}$mutant were smaller. In contrast, tissue maceration of pods, which occurs at a later stage of infection, was completely abolished in the AHL-deficient mutants. Both the incidence of disease and in planta growth of $P$. syringae pv. tabaci were greatly reduced in transgenic tobacco plants that produced AHL compared with wild-type plants. These results demonstrate that quorum sensing in $P$. syringae regulates traits that contribute to epiphytic fitness as well as to distinct stages of disease development during plant infection.
\end{abstract}

Additional keywords: cell-to-cell signaling, GacA, swarming.

Pseudomonas syringae pv. syringae strains are the causal agent of brown spot disease of bean and incite frost injury to plants (Hirano and Upper 2000). Before initiating disease, $P$. syringae strains achieve large epiphytic population sizes on healthy leaves (Rouse et al. 1985). Understanding the factors that enable this epiphytic bacterium to successfully colonize leaf surfaces should lead to better strategies for the control of plant disease or frost injury. Recently, it has been demonstrated that the majority of cells of $P$. syringae strain $\mathrm{B} 728 \mathrm{a}$

Corresponding author: S. E. Lindow; Telephone: +1.510.642.4174; Fax: +1.510.642.4995; E-mail: icelab@socrates.berkeley.edu

Current address of B. Quiñones: United States Department of Agriculture, Agricultural Research Service, Produce Safety and Microbiology Unit, 800 Buchanan Street, Albany, CA 94710, U.S.A.

B. Quiñones and G. Dulla contributed equally to this work. occur in aggregates on leaves rather than as solitary cells (Monier and Lindow 2004). Cells in aggregates exhibited a much greater ability to survive periodic desiccation stress on leaves (Monier and Lindow 2003). Interestingly, increased tolerance to desiccation was related directly to the size of the cell aggregate (Monier and Lindow 2003). These findings suggest that some aspects of the epiphytic fitness of $P$. syringae are cell-density-dependent and that the preferential expression of certain traits within aggregated cells contributes to plant colonization.

Bacterial populations are capable of coordinating the expression of some traits in a cell-density-dependent manner by a process known as quorum sensing (Loh et al. 2002; Von Bodman et al. 2003). Bacteria that use quorum sensing can assess their local population density by detecting the production of a diffusible signal molecule which increases with local population density, resulting in coordinated gene expression. $P$. syringae and many other gram-negative bacteria use $N$-acyl homoserine lactone (AHL) as the quorum-sensing signal molecule. In many pathogenic bacteria, elevated levels of AHL, due to higher population densities, result in the expression of virulence factors and secondary metabolites that mediate successful colonization of the host.

The quorum-sensing system in $P$. syringae has many similarities to that of other gram-negative bacteria. The production of $P$. syringae's AHL signal, 3-oxo-hexanoyl-homoserine lactone (3-oxo-C6-HSL), occurs in a cell-density-dependent fashion and requires the expression of the AHL synthase gene, ahlI, and the AHL regulator gene, ahlR (Dumenyo et al. 1998; Quiñones et al. 2004). In the presence of cellular precursors, AhlI catalyzes the production of 3-oxo-C6-HSL. AhlR forms a stable complex with the AHL signal and activates transcription of ahlI via a positive-feedback mechanism that leads to higher amounts of AHL to be produced with increasing cell concentrations. This AhlI-AhlR quorum-sensing system also is subject to modulation by additional regulatory proteins (Dumenyo et al. 1998; Kitten et al. 1998; Quiñones et al. 2004). Our previous work identified AefR as an important and novel regulator of quorum sensing in P. syringae (Quiñones et al. 2004). AefR was required for transcription of ahlI and, consequently, for maximal levels of AHL production. Another regulator, GacA, had a similar effect on the autoinduction process (Dumenyo et al. 1998; Kitten et al. 1998; Quiñones et al. 2004). Both AefR and GacA are thought to act as activators of the AhlI-AhlR quorum-sensing system via independent pathways (Quiñones et al. 2004).

AHL-mediated quorum sensing plays a major role in the interaction between plants and microbes (Loh et al. 2002; Von Bodman et al. 2003). Quorum sensing is required for the ex- 
pression of virulence factors and secondary metabolites in plant-pathogenic bacteria that contribute to colonization of plants and subsequent disease. For example, quorum sensing in Erwinia carotovora is required for the expression of several exoenzymes that are responsible for the maceration of plant tissues (Jones et al. 1993; Pirhonen et al. 1993). In Pantoea stewartii, AHL-mediated gene expression is involved in the production of the exopolysaccharide (EPS) virulence factor, stewartan (Beck von Bodman and Farrand 1995; Beck von Bodman et al. 1998). Other cell-density-dependent traits in plant-pathogenic bacteria recently have been reviewed (Von Bodman et al. 2003).

The role of AHL production in the expression of densitydependent traits that contribute to epiphytic fitness and virulence of Pseudomonas syringae has not yet been characterized fully. Although recent findings showed that disruption of ahlI results in an altered morphology of $P$. syringae colonies on solid agar (Kinscherf and Willis 1999), quorum sensing was reported not to have an effect on the production of virulence factors such as extracellular proteases or the phytotoxin syringomycin (Dumenyo et al. 1998; Kinscherf and Willis 1999). Furthermore, an $a h l I^{-}$mutant was reported to retain swarming motility and virulence on bean leaves (Kinscherf and Willis 1999), traits that are positively regulated in an AHL-dependent manner in other bacteria. To further understand the contribution of cell-to-cell signaling in $P$. syringae on epiphytic fitness and virulence, the present study examined the dependence of diverse behaviors on quorum sensing. We provide evidence that both the AhlI-AhlR quorum-sensing system and AefR are positive regulators of EPS production, oxidative stress tolerance, and plant tissue maceration, as well as negative regulators of swarming motility. In addition, this complex regulation of behaviors results in either increased or decreased early watersoaked lesions on bean pods and disease symptoms on leaves, depending on the environmental conditions. We also demonstrate that pathogen growth and disease incidence are altered in transgenic plants capable of producing 3-oxo-C6-HSL, the AHL that is recognized by $P$. syringae.

\section{RESULTS}

\section{EPS production and resistance to oxidative stress} is impaired in AHL-deficient mutants of $P$. syringae.

The production of EPS is subject to regulation by quorum sensing in several phytopathogenic bacteria (Von Bodman et al. 2003); therefore, we examined the production of alginate in various mutants of $P$. syringae deficient in AHL production. Strains were grown on mannitol-glutamate solidified medium supplemented with yeast extract at $0.25 \mathrm{~g} /$ liter (MGY) in the presence of $0.6 \mathrm{M}$ sorbitol, a medium previously demonstrated to promote a mucoid phenotype and a maximal expression of the alginate biosynthetic gene cluster in $P$. syringae (Peñaloza-
Vázquez et al. 1997; Willis et al. 2001). Wild-type $P$. syringae strain B728a exhibited a mucoid, slimy colony type after growth for 3 days under these conditions, whereas an $a h l I^{-}$ $a h l R^{-}$double mutant and an $a e f R^{-}$mutant both exhibited a reduced mucoid phenotype (data not shown). As expected, a $g a c A^{-}$mutant had a dry, nonmucoid colony type, as previously reported (Willis et al. 2001). We then performed a modified carbazol assay to quantify the amounts of alginate produced by the wild-type and AHL-deficient mutant strains. The amount of alginate produced by an $a h l I^{-} a h l R^{-}$double mutant was threefold less than that produced by wild-type cells (Table 1). Furthermore, the amount of alginate recovered from an aefR ${ }^{-}$ mutant was approximately fourfold less than that from wildtype cells (Table 1). No alginate was isolated from a $\mathrm{gacA}^{-}$ mutant, confirming that the GacS/GacA two-component regulator is required for alginate biosynthesis (Willis et al. 2001). The fact that both the $a h l I^{-} a h l R^{-}$double mutant and an $a e f R^{-}$ mutant had an impaired but not abolished alginate production suggests that the AhlR and AefR regulators are not required for, but contribute to, maximal levels of alginate production in P. syringae.

To further characterize the defect in alginate production observed in AHL-deficient mutants of $P$. syringae, we assessed whether an $a e f R^{-}$mutant or an $a h l I^{-} a h l R^{-}$double mutant showed increased susceptibility to hydrogen peroxide, a compound known to generate reactive oxygen intermediates (ROIs) (Farr and Kogoma 1991). Previous studies demonstrated that a $P$. syringae mutant deficient in alginate biosynthesis was hypersensitive to environmental stresses, such as heat and compounds that generate ROIs (Keith and Bender 1999). An increased susceptibility to ROIs was observed in the AHL-deficient mutants, as evidenced by a larger zone of growth inhibition around discs that were impregnated with a hydrogen peroxide solution (Table 1). The zones of growth inhibition of both an $a e f R^{-}$and an $a h l I^{-} a h l R^{-}$double mutant were similar to each other, but significantly greater than that exhibited by wild-type cells (Table 1). Interestingly, a $g a c A^{-}$mutant was even more susceptible to ROIs than either of the AHL-deficient mutants (Table 1).

\section{Swarming motility is enhanced in AHL-deficient mutants.}

When inoculated onto filters at a cell concentration of $1 \times$ $10^{7}$ cells/filter, wild-type cells of $P$. syringae showed limited swarming motility on a low-agar medium (Fig. 1). Wild-type cells displayed only an irregular blebbing that appeared at the margin of the colony. An $a h l I^{-} a h l R^{-}$double mutant exhibited much more motility and an irregular dendritic colony pattern that spread rapidly away from the point of inoculation when compared with the wild-type strain (Fig. 1). Interestingly, an aef $R^{-}$mutant swarmed the greatest distance from the point of inoculation and displayed more extended tendrils that occurred in a very regular and defined dendritic pattern (Fig. 1). The

Table 1. Alginate production and susceptibility to reactive oxygen intermediates in Pseudomonas syringae strains differing in $N$-acyl homoserine lactone (AHL) production

\begin{tabular}{|c|c|c|c|}
\hline Strain & Genotype & $\begin{array}{c}\text { Alginate production } \\
(\mu \mathrm{g} / \mathrm{mg} \text { of total protein } \pm \mathrm{SD})^{\mathrm{y}}\end{array}$ & $\begin{array}{c}\text { Hydrogen peroxide susceptibility } \\
\text { (growth inhibition zone }[\mathrm{mm}] \pm \mathrm{SD})^{\mathrm{z}}\end{array}$ \\
\hline B728a & Wild type & $913.84 \pm 108.83 \mathrm{a}$ & $11.38 \pm 0.51 \mathrm{a}$ \\
\hline A9 & ahlI $a h l R^{-}$ & $302.94 \pm 58.82 \mathrm{~b}$ & $13.69 \pm 0.48 b$ \\
\hline 538 & $a e f R^{-}$ & $225.65 \pm 63.71 \mathrm{~b}$ & $13.15 \pm 0.68 b$ \\
\hline BGACX & $g a c A^{-}$ & $17.89 \pm 4.98 \mathrm{c}$ & $18.23 \pm 0.44 \mathrm{c}$ \\
\hline
\end{tabular}

${ }^{\mathrm{y}}$ Alginate production was quantified after growth for 3 days on mannitol-glutamate solidified medium supplemented with yeast extract at 0.25 g/liter containing 0.6 M sorbitol. Results are the mean and the standard deviation (SD) from a single experiment consisting of three replicates. Values followed by the same letter were not significantly different at $P=0.01$ according to Bonferroni's means comparison test.

${ }^{\mathrm{z}}$ Susceptibility to reactive oxygen intermediates was determined by measuring the diameter of the growth inhibition zone surrounding filters containing $3 \%$ hydrogen peroxide. Results are the mean and standard deviation from a single experiment consisting of five replicates. Values followed by the same letter were not significantly different at $P=0.01$ according to Bonferroni's means comparison test. 
aef $R^{-}$mutant swarmed approximately 2.5 -fold farther than an $a h l I^{-} a h l R^{-}$double mutant and 5.6-fold farther than the wildtype strain (Table 2).

When the wild-type and AHL-deficient mutants were spotted at a higher cell concentration $\left(1 \times 10^{9}\right.$ cells/filter $)$, the differences in swarming motility among the strains were less pronounced (Fig. 1, bottom panels). Wild-type cells exhibited greater swarming motility after an overnight incubation than when a smaller number of cells were spotted. However, the $a h l I^{-}$ahlR ${ }^{-}$double mutant strain was still more motile than the wild type (Fig 1; Table 2). Moreover, an aefR $R^{-}$mutant was the most hypermotile even when inoculated at these higher inoculum concentrations (Fig. 1), moving approximately twofold farther than the wild-type strain (Table 2). As expected from previous studies (Kinscherf and Willis 1999), no swarming motility was observed for a $g a c A^{-}$mutant at any cell concentration tested in this assay (Fig. 1). Because a more pronounced effect was observed at relatively lower cell densities, these results demonstrate that the AhlI-AhlR quorum-sensing system and the regulator AefR both apparently repress swarming motility, especially during the early stages of quorum sensing.

To further dissect the differences in swarming motility observed between the wild-type strain and AHL-deficient mutants of $P$. syringae, their speed of movement was examined on a low-agar medium. At a given time, each of the strains exhibited substantial differences in the distance to which they moved. An aefR $R^{-}$mutant was hypermotile and moved the farthest. This strain was the first to begin movement, approximately $5 \mathrm{~h}$ after inoculation (Fig. 2). An $a h l I^{-} a h l R^{-}$double mutant moved less distance than an $a e f R^{-}$mutant, but substantially more than the wild-type strain, and initiated swarming motility approximately 8 to $9 \mathrm{~h}$ after inoculation. No motility was observed in a $g a c A^{-}$mutant (Fig. 2). To further compare swarming motility among the various strains, the rates of movement were obtained by calculating the slope of the bestfit line relating the swarmed distance as a function of time
(Fig. 2). The rates of movement for both an aefR $R^{-}$mutant and an $a h l I^{-} a h l R^{-}$double mutant were constant with time and similar to each other $(0.13 \mathrm{~cm} / \mathrm{h})$. In contrast, the wild-type strain had a slower rate of movement $(0.07 \mathrm{~cm} / \mathrm{h})$.

Quorum-sensing mutants invade leaves more rapidly.

Because AHL-deficient strains of $P$. syringae were hypermotile in culture, we investigated whether they also had an increased ability to invade leaves. To address this question, the surface of bean leaves was spray inoculated with each strain to establish similar initial epiphytic bacterial populations. At various time points after inoculation, we assessed the invasion into the leaf tissue by measuring the internal populations that were protected from hydrogen peroxide killing, as in previous studies (Wilson et al. 1999). The aefR ${ }^{-}$mutant and the $a h l I^{-}$ahlR double mutant strain both had an increased ability to invade the leaf tissue (Fig. 3). When examined 3 or $6 \mathrm{~h}$ after inoculation, the hydrogen peroxide-insensitive population sizes for both of these mutant strains were more than $10^{3} \mathrm{CFU} / \mathrm{leaf}$,

Table 2. Swarming motility of Pseudomonas syringae strains differing in $\mathrm{N}$-acyl homoserine lactone (AHL) production

\begin{tabular}{|c|c|c|c|}
\hline \multirow[b]{2}{*}{ Strain } & \multirow[b]{2}{*}{ Genotype } & \multicolumn{2}{|c|}{ Distance swarmed $(\mathrm{mm}) \pm \mathrm{SD}^{y}$} \\
\hline & & $1 \times 10^{7}$ cells/filter ${ }^{\mathrm{z}}$ & $1 \times 10^{9}$ cells $/$ filter $^{\mathrm{Z}}$ \\
\hline B728a & Wild type & $2.50 \pm 0.78 \mathrm{a}$ & $15.83 \pm 3.85 \mathrm{a}$ \\
\hline A9 & $a h l I^{-} a h l R^{-}$ & $5.67 \pm 1.45 b$ & $19.56 \pm 3.22 b$ \\
\hline 538 & $a e f R^{-}$ & $14.11 \pm 4.02 \mathrm{c}$ & $29.17 \pm 3.49 \mathrm{c}$ \\
\hline BGACX & $g a c A^{-}$ & ND & ND \\
\hline
\end{tabular}

${ }^{y}$ Swarming motility was assessed after growth on King's B agar containing $0.4 \%$ agar for $16 \mathrm{~h}$ at $26^{\circ} \mathrm{C}$. Results are the mean and standard deviation from a single experiment consisting of three replicates. Values followed by the same letter within a given inoculum were not significantly different at $P=0.01$ according to Bonferroni's means comparison test. $\mathrm{ND}=$ Not detected

${ }^{\mathrm{z}}$ Inoculum concentration applied to filter disc.
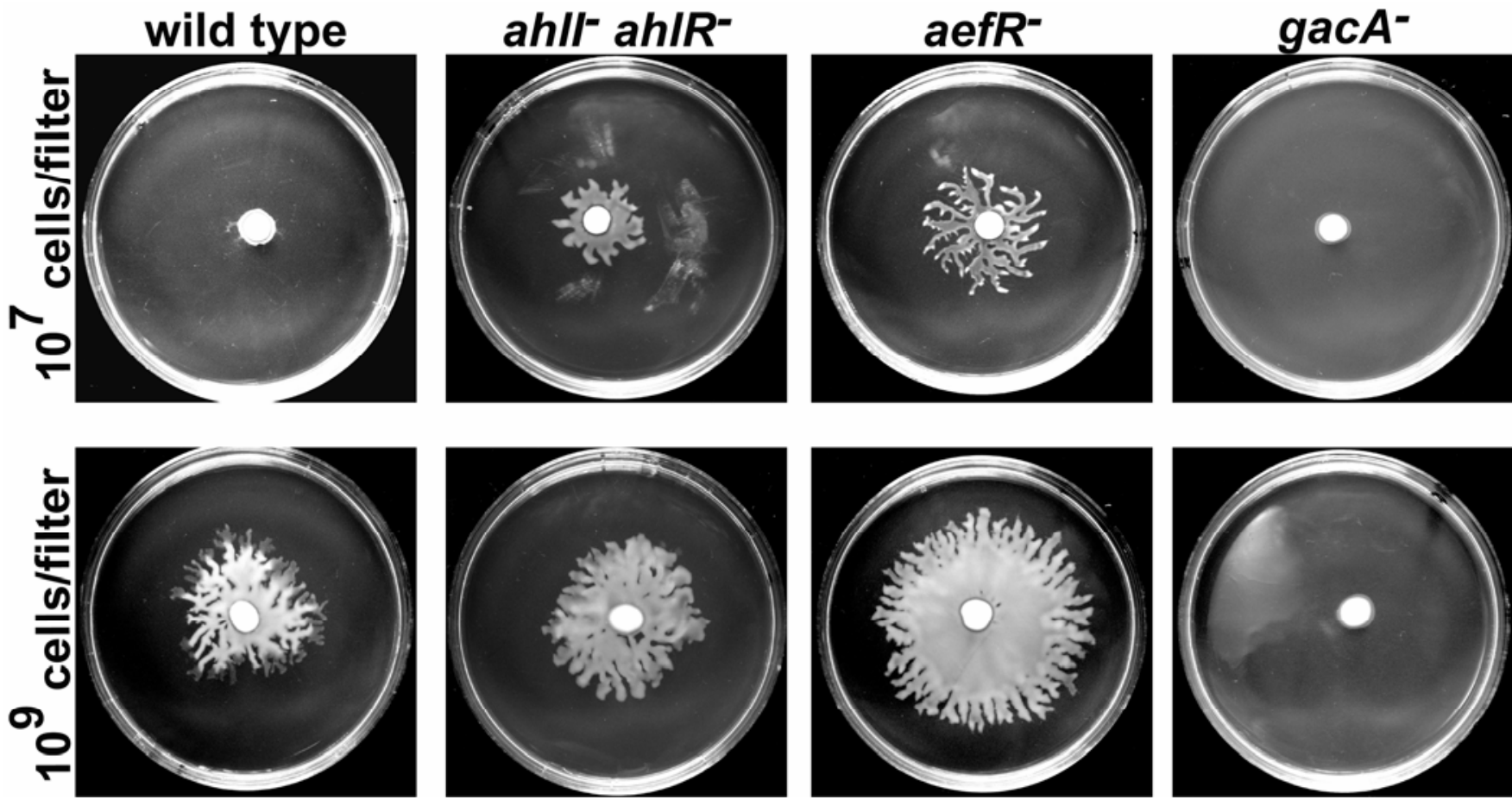

Fig. 1. Swarming motility is enhanced in $N$-acyl homoserine lactone (AHL)-deficient mutants of Pseudomonas syringae. Sterile filter discs were inoculated with either $1 \times 10^{7}$ cells (top panels) or with $1 \times 10^{9}$ cells (bottom panels) of $P$. syringae parental strain B728a, ahlI $I^{-}$ahlR $R^{-}$double mutant strain A9, aefR ${ }^{-}$ mutant strain 538 , or gac $A^{-}$mutant strain BGACX and placed on King's B agar containing $0.4 \%$ agar. Plates were incubated at $26^{\circ} \mathrm{C}$ for 16 h. Results are from a single representative experiment with three replicates. 
1,000-fold higher than that of wild-type cells. Only very small internal populations of the wild-type strain were detected by 6 $\mathrm{h}$ after inoculation (Fig. 3). Similarly, no cells of a $\mathrm{gacA}^{-} \mathrm{mu}-$ tant were detected in sites on the leaves protected from hydrogen peroxide within the first $6 \mathrm{~h}$ of colonization (Fig. 3). After $18 \mathrm{~h}$, the internal population sizes for each strain were relatively large; however, the population sizes of an aef $R^{-}$mutant often were higher than the other strains (Fig. 3). The epiphytic population sizes of both wild-type and AHL-deficient mutant strains were similar for each strain at a given sampling time, ranging from $1 \times 10^{5} \mathrm{CFU} /$ leaf to more than $10^{6} \mathrm{CFU} / \mathrm{leaf}$ (data not shown). These observations suggest that the low internal population of the wild-type and $\mathrm{gacA}^{-}$mutant strain was due to their inability to actively enter leaves and was not due to a lack of viable cells on the leaf surface. Thus, the hypermotile $a e f R^{-}$and $a h l I^{-} a h l R^{-}$mutants have an enhanced ability to explore and invade protected sites on leaves during the early stages of colonization.

\section{Quorum sensing in $P$. syringae influences virulence toward bean.}

We examined the contribution of the AhlI-AhlR quorumsensing system and of AefR in the formation of brown spot lesions on bean leaves. P. syringae strain B728a produces small brown necrotic lesions surrounded by a yellow halo of chlorotic tissue that are easily enumerated (Hirano and Upper 2000); therefore, we compared the virulence of various AHLdeficient mutants after spray inoculation of leaves. Plants were incubated under moist conditions for either 24 or $48 \mathrm{~h}$ (short or long treatment, respectively) to achieve high $\left(10^{7} \mathrm{CFU} /\right.$ leaf $)$ and stable epiphytic population sizes before being transferred to a greenhouse to allow lesions to form for 7 days. Visible brown spot lesions were quantified only on trifoliate leaves that were fully expanded at the time of inoculation. The results obtained demonstrated that the number of brown spot lesions on leaves treated with the wild-type, $a e f R^{-}$, or $a h l I^{-} a h l R^{-}$mutant strains did not significantly differ when exposed to moist conditions for only 1 day (Fig. 4). However, when plants were

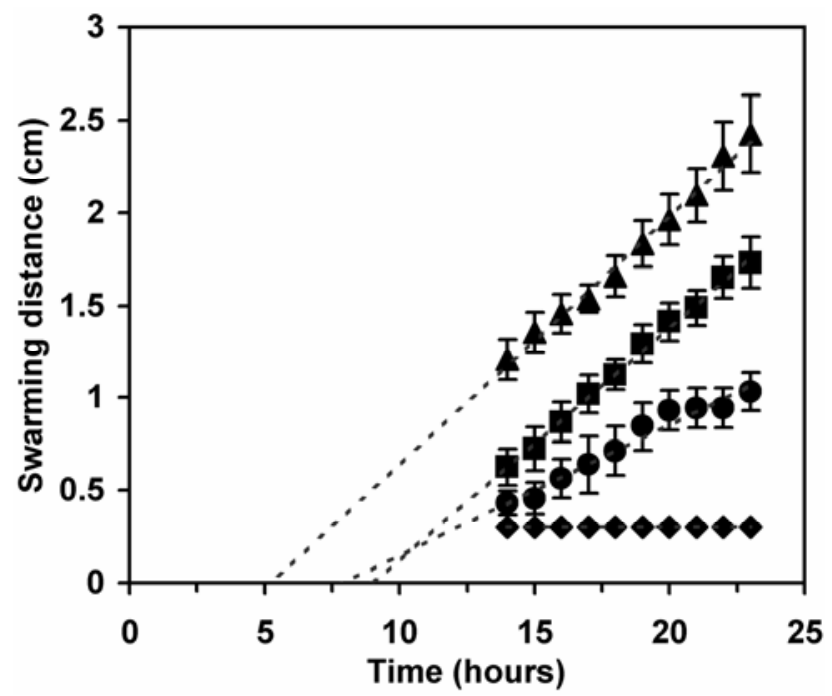

Fig. 2. Rate of swarming motility in wild-type and $N$-acyl homoserine lactone (AHL)-deficient mutants of Pseudomonas syringae. Swarming motility was assessed on King's B agar containing $0.4 \%$ agar after inoculating sterile filter discs with $10^{7}$ cells of $P$. syringae parental strain

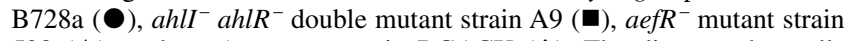
$538(\mathbf{A})$, and $g a c A^{-}$mutant strain $\operatorname{BGACX}(\bullet)$. The distance that cells moved from the point of inoculation was measured every hour. Results are from a single representative experiment with three replicates. Vertical bars represent the standard deviation from the mean. incubated for 2 days under moist conditions, both an aefR mutant and an $a h l I^{-} a h l R^{-}$double mutant incited more lesions than the wild-type strain (Fig. 4). Lesions incited by the $a h l I^{-}$ $a h l R^{-}$double mutant strain were threefold higher, whereas the $a e f R^{-}$mutant strain incited nearly sevenfold more lesions than the wild type after an extended moist period (Fig. 4). As previously reported (Rich et al. 1994), a gacA ${ }^{-}$mutant was avirulent under all conditions tested in this study (Fig. 4).

To further investigate whether the AhlI-AhlR quorum-sensing system and AefR regulate factors required for early stages of symptom development, bean pods with superficial incisions were inoculated with the wild-type and AHL-deficient mutant strains. When injected into bean pods, $P$. syringae causes sunken water-soaked lesions that are indicative of tissue necrosis and fluid release within 2 days of infection (Willis et al. 1990). After incubation under humid conditions, the diameters of the water-soaked lesions were measured at the site of inoculation. Although all strains incited water-soaked lesions, the sizes of the lesions were different for each strain. When compared with the wild-type strain, the water-soaked lesions on bean pods inoculated with an $a h l I^{-} a h l R^{-}$double mutant were $20 \%$ larger; in contrast, the lesions incited by an aefR $R^{-}$mutant were $41 \%$ smaller (Fig. 5). A gac $A^{-}$mutant did not cause watersoaked lesions on bean pods (Fig. 5). These findings demonstrate that the AhlI-AhlR quorum-sensing system and AefR have distinct roles in the initiation of early disease symptoms on bean.

Some bacterial plant pathogens, such as Erwinia spp., express enzymes involved in plant tissue maceration that contribute to disease symptoms under quorum-sensing control (Von Bodman et al. 2003; Whitehead et al. 2001). To determine whether this mechanism also occurs in $P$. syringae, internal disease symptoms were examined in bean pods that were inoculated as above. After incubation for 3 to 4 days at $28^{\circ} \mathrm{C}$, the pods were cross-sectioned longitudinally to examine the integrity of internal tissues. The wild-type strain B728a caused extensive internal tissue maceration and partial dehydration (Fig. 6). In contrast, both an $a h l I^{-}$ahlR $R^{-}$double mutant and an aefR ${ }^{-}$mutant did not cause any internal tissue maceration (Fig. 6). Pods inoculated with these strains remained green, fleshy, and indistinguishable from those inoculated with the $g_{a c A^{-}}$mutant

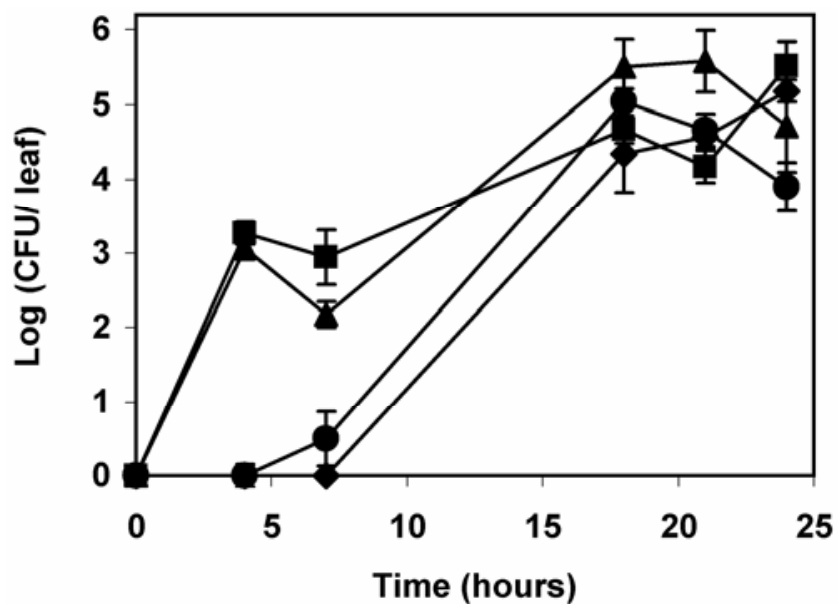

Fig. 3. Analysis of movement by wild-type and $N$-acyl homoserine lactone (AHL)-deficient mutants of Pseudomonas syringae into hydrogen peroxide-protected sites after inoculation onto bean leaves. The population sizes of $P$. syringae parental strain B728a ( ), ahlI $a h l R^{-}$double mutant strain A9 (ם), aefR ${ }^{-}$mutant strain $538(\mathbf{\Delta})$, and $\mathrm{gacA}^{-}$mutant strain $\operatorname{BGACX}(\diamond)$ from macerated bean leaves that were surface sterilized with hydrogen peroxide at various times are shown. Results are from a single representative experiment with three replicates. Vertical bars represent the standard error of the mean of $\log _{10}$-transformed bacterial population sizes. 
strain or with buffer alone (Fig. 6). A lack of tissue maceration also was observed when bean pods were inoculated with an ahlI $I^{-}$mutant (data not shown). Based on these observations, quorum sensing in $P$. syringae appears to be required for the expression of virulence determinants that are responsible for internal tissue maceration.

\section{Exogenous AHL confers resistance}

\section{to $P$. syringae pv. tabaci in tobacco.}

In $P$. syringae strain $\mathrm{B} 728 \mathrm{a}$, quorum sensing appears to regulate virulence toward bean; therefore, we explored whether altering the abundance of AHL within the plant could modulate disease. To investigate this, we inoculated transgenic tobacco plants that produce 3-oxo-C6-HSL (Fray 2001). Because tobacco is not a host for $P$. syringae $\mathrm{B} 728 \mathrm{a}$, we tested virulence using $P$. syringae pv. tabaci strain $11528 \mathrm{R}$, a causal agent of wild fire disease in tobacco (Dye et al. 1980). 3-oxoC6-HSL has been shown to regulate quorum sensing in $P$. syringae pv. tabaci (Shaw et al. 1997), and the genes required for 3-oxo-C6-HSL production show high sequence identity to those in strain B728a (Quiñones et al. 2004). Various cell concentrations of this strain were infiltrated into the leaf apoplast of transgenic and wild-type tobacco, and disease symptoms were evaluated daily. Symptoms were first observed 2 days after inoculation only in plants that were inoculated with the highest cell concentrations $\left(10^{7}\right.$ and $\left.10^{9} \mathrm{CFU} / \mathrm{ml}\right)$ and were confined to the areas infiltrated with the pathogen (data not shown). Although necrotic leaf tissue was observed in both wild-type and AHL-producing transgenic plants, lesions in wild-type tobacco plants were much more chlorotic. By 3 days after inoculation, disease symptoms in wild-type tobacco were much more pronounced than in AHL-producing plants when inoculated with $10^{5} \mathrm{CFU} / \mathrm{ml}$ (Fig. 7). A similar, but subtler, difference in disease symptoms was observed between the transgenic and the wild-type plants when inoculated with an even higher cell concentration $\left(10^{7}\right.$ and $\left.10^{9} \mathrm{CFU} / \mathrm{ml}\right)$ (Fig. 7). Interestingly, leaves of wild-type plants that were inoculated with $10^{3} \mathrm{CFU} / \mathrm{ml}$ had

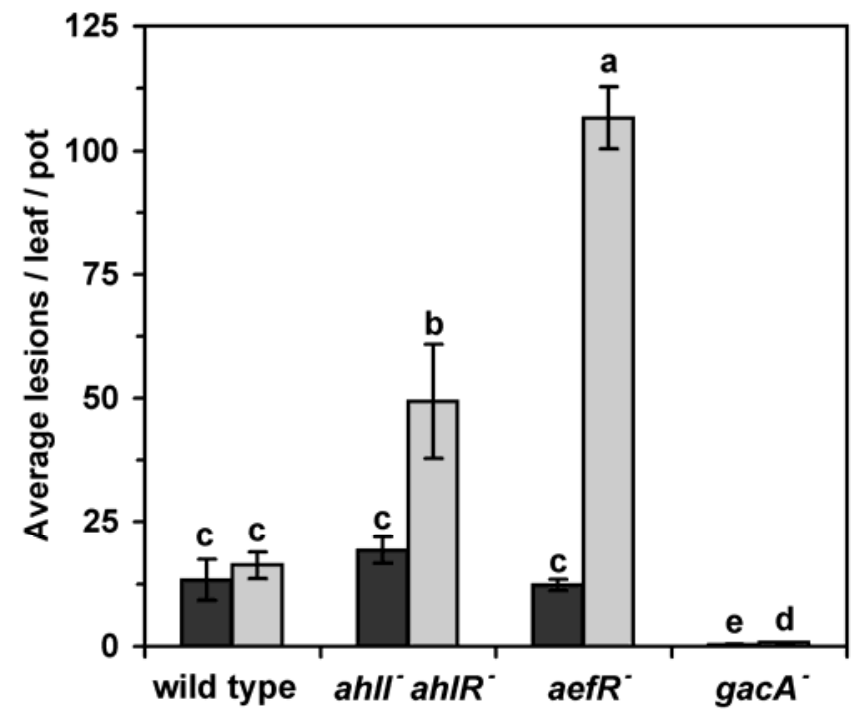

Fig. 4. Lesion formation on bean leaves inoculated with an $a e f R^{-}$mutant and an $a h l I^{-}$ahlR ${ }^{-}$double mutant of Pseudomonas syringae. Bean leaves were spray inoculated with a cell suspension containing $10^{6} \mathrm{CFU} / \mathrm{ml}$ of $P$. syringae parental strain $\mathrm{B} 728 \mathrm{a}, a h l I^{-}$ahlR $R^{-}$double mutant strain A9, aefR $R^{-}$mutant strain 538, or $g a c A^{-}$mutant strain BGACX. Plants were incubated under high relative humidity for either $24 \mathrm{~h}$ (black bars) or $48 \mathrm{~h}$ (gray bars) at $28^{\circ} \mathrm{C}$ and brown spot lesions were counted after 7 days. Bars with the same letter were not significantly different $(P<0.01)$ according to Duncan's multiple range test. some chlorotic areas with discrete tissue necrosis, whereas AHL-producing transgenic plants exhibited no disease symptoms (Fig. 7). However, by 5 days after inoculation, symptoms on AHL-producing and wild-type plants were similar at any given inoculum concentration. Thus, exogenous AHL conferred a decreased susceptibility to $P$. syringae pv. tabaci in tobacco, particularly at early stages of infection with low inoculum concentrations.

To address how exogenous AHL suppressed disease, growth of $P$. syringae pv. tabaci strain 11528R was compared within wild-type and AHL-producing tobacco. No differences in pathogen growth in AHL-producing and wild-type plants was observed at any sampling time when plants were inoculated with a cell concentration of $1 \times 10^{5} \mathrm{CFU} / \mathrm{ml}$, resulting in an initial population of approximately $10^{3} \mathrm{CFU} /$ leaf disc (Fig. 8). A rapid 1,000-fold increase in pathogen abundance was observed within 1 day after inoculation and a further 10-fold increase occurred by 2 days. Interestingly, when a low population (approximately $10^{2} \mathrm{CFU} /$ leaf disc) was established, a difference in pathogen growth was observed between transgenic and wild-type plants (Fig. 8). By 1 day after inoculation, the population sizes of strain $11528 \mathrm{R}$ were found to be slightly lower in tobacco plants producing 3-oxo-C6-HSL than in wildtype plants. The population sizes of $11528 \mathrm{R}$ remained as much as 10-fold lower in AHL-producing transgenic plants when compared with wild-type plants for two or more days (Fig. 8).

The effect of exogenous AHL on the disease process was further assessed after establishing an epiphytic population of the pathogen on wild-type and AHL-producing tobacco. Strain 11528 was spray inoculated on transgenic and control tobacco plants, and the incidence of leaf spot lesions was recorded after incubating plants under moist conditions. The number of leaf lesions on AHL-producing tobacco was 3.6-fold lower than on wild-type plants (Fig. 9). Based on these observations, production of AHL on tobacco leaves effectively reduces spot lesion formation from epiphytic populations of $P$. syringae pv. tabaci strain 11528.

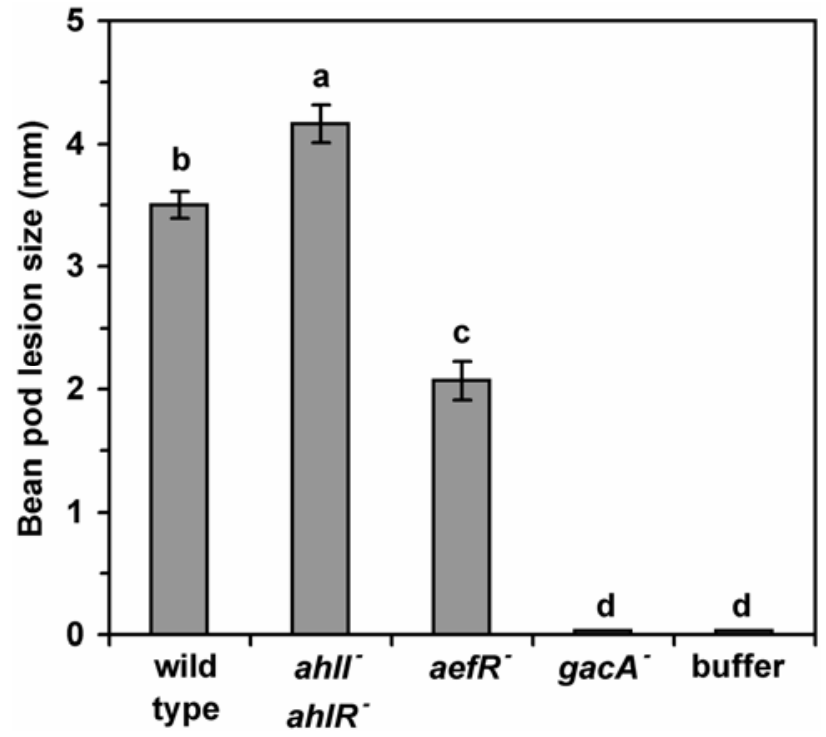

Fig. 5. Sizes of water-soaked lesions on bean pods produced by wild-type and $\mathrm{N}$-acyl homoserine lactone (AHL)-deficient mutants of Pseudomonas syringae. Wounded bean pods were inoculated with a drop containing $10^{8}$ cells of $P$. syringae parental strain $\mathrm{B} 728 \mathrm{a}$, $a h l I^{-}$ahlR $R^{-}$double mutant strain A9, aefR $R^{-}$mutant strain 538, or $g a c A^{-}$mutant strain BGACX. The diameter of the water-soaked lesions was measured after 3 days of incubation under moist conditions at $28^{\circ} \mathrm{C}$. Bars with the same lowercase letter were not significantly different $(P<0.01)$ according to Bonferroni's means comparison test. 


\section{DISCUSSION}

The production of EPS by plant-pathogenic bacteria is considered to be an important strategy that contributes significantly to their growth, survival, and virulence (Lindow and Brandl 2003; Loh et al. 2002; Von Bodman et al. 2003). EPS production in Pantoea stewartii, Ralstonia solanacearum, and Xanthomonas campestris is subject to regulation by quorum sensing (Von Bodman et al. 2003). Based on these observations, the present study examined whether quorum sensing contributes to the production of alginate, a major component of EPS in Pseudomonas syringae strain B728a. Various AHLdeficient mutants of $P$. syringae B728a were significantly impaired in alginate production (Table 1). Both an aefR $R^{-}$mutant and an ahlI $^{-}$ahlR $R^{-}$double mutant produced $30 \%$ less alginate than the parental strain. Although an $a h l I^{-}$mutant previously was reported to be unaffected in alginate production (Willis et al. 2001), our study clearly demonstrated that, although AHLdeficient mutants are not devoid of alginate, AefR and the AhlI-AhlR quorum-sensing system contribute to maximal levels of alginate production. Our finding that alginate production in $P$. syringae strain B728a is regulated in an AHL-dependent

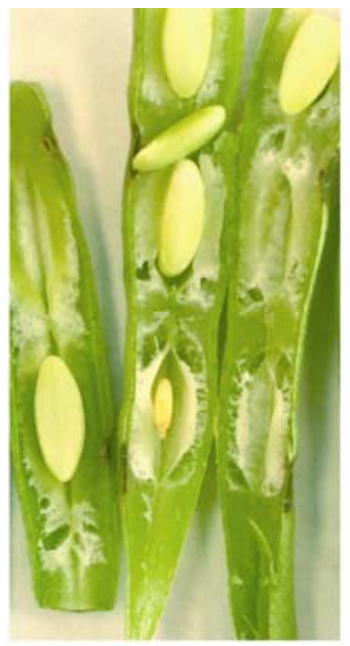

wild type

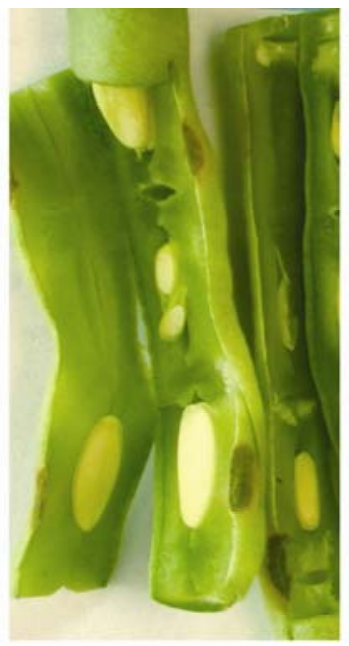

ahI' $a h I R^{-}$

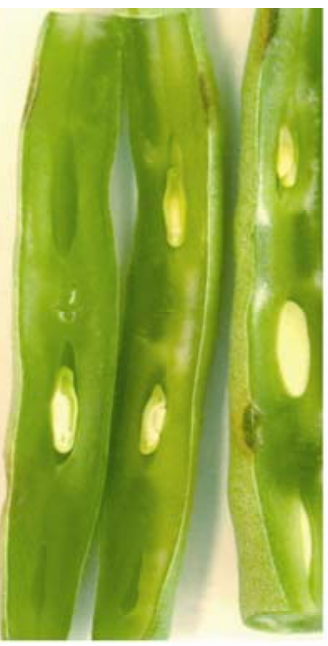

aefR-

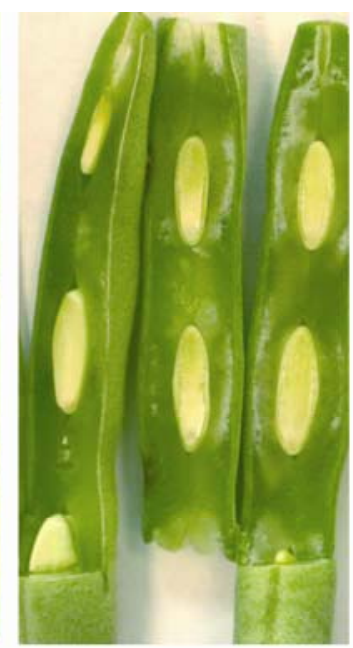

$\operatorname{gacA}^{-}$

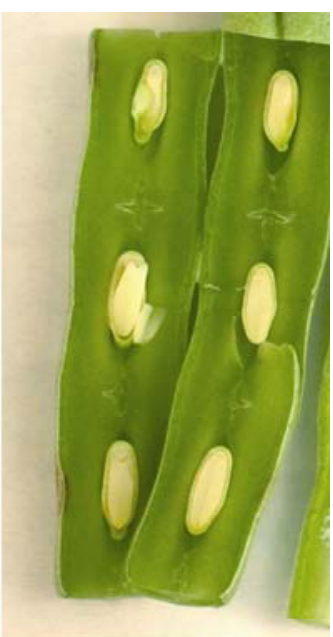

buffer

Fig. 6. Bean tissue maceration is abolished in $N$-acyl homoserine lactone (AHL)-deficient mutants of Pseudomonas syringae. Bean pods were inoculated with a drop containing $5 \times 10^{7}$ cells of $P$. syringae parental strain $\mathrm{B} 728 \mathrm{a}$, ahlI- ahlR $^{-}$double mutant strain $\mathrm{A} 9$, aefR ${ }^{-}$mutant strain 538 , or gacA- mutant strain BGACX and incubated at $28^{\circ} \mathrm{C}$ for 3 days. Internal tissue maceration was examined after performing a longitudinal cross section of the pods.

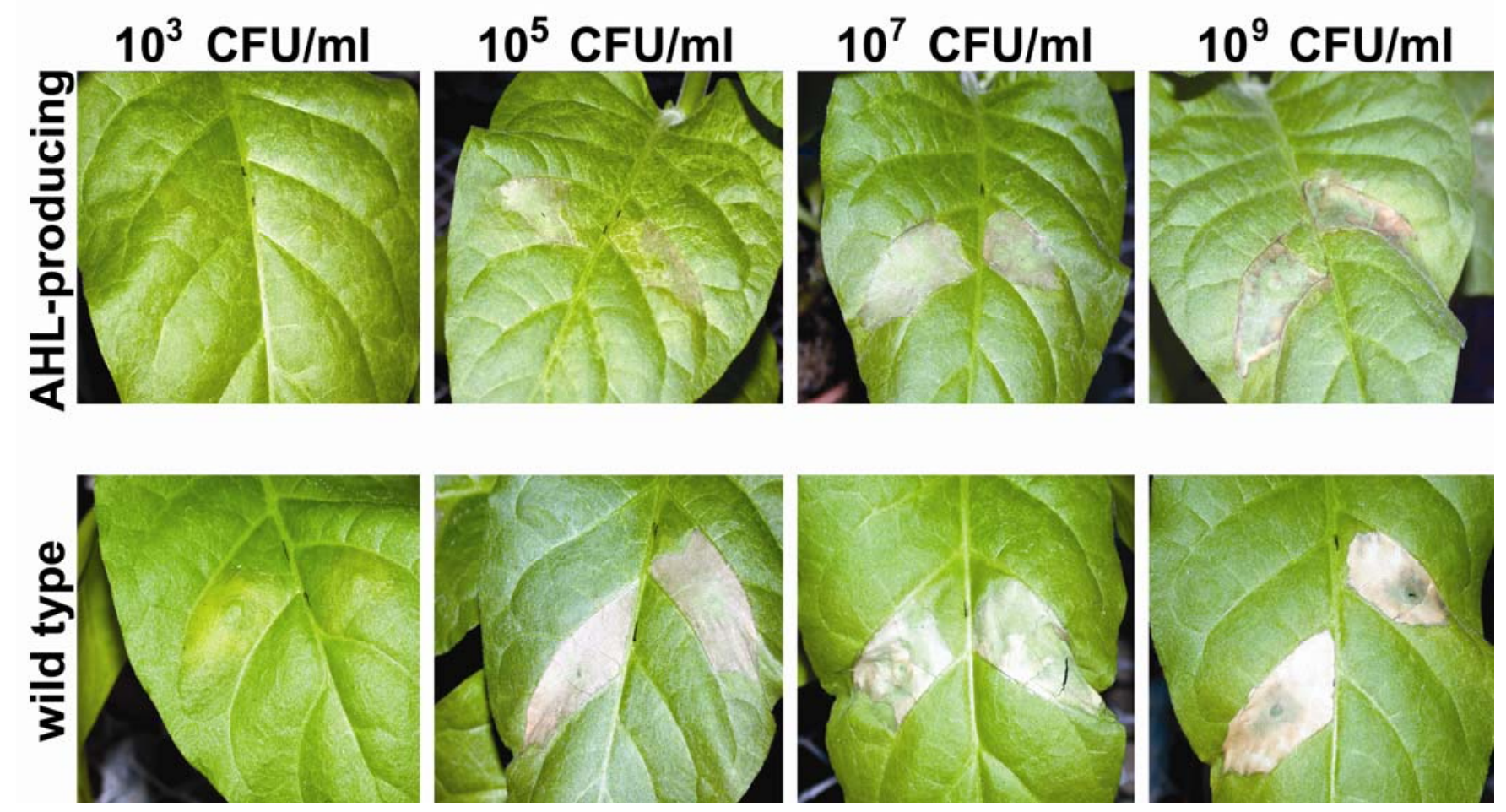

Fig. 7. Leaf symptoms on $\mathrm{N}$-acyl homoserine lactone (AHL)-producing and wild-type tobacco plants by Pseudomonas syringae pv. tabaci. Regions between lateral veins on tobacco leaves were infiltrated with $P$. syringae pv. tabaci $11528 \mathrm{R}$ at various cell concentrations: $10^{3}, 10^{5}, 10^{7}$, or $10^{9} \mathrm{CFU} / \mathrm{ml}$. Disease symptoms were assessed 3 days after inoculation. Results shown are from a single representative experiment with 15 replicates for each inoculum concentration tested. 
manner helps explain the cell-density-dependent, epiphytic fitness that is exhibited by this strain (Quiñones et al. 2004). An association between alginate synthesis and susceptibility to hydrogen peroxide also was observed (Table 1). The increased susceptibility to hydrogen peroxide of an aefR ${ }^{-}$and an $a h l I^{-}$ $a h l R^{-}$double mutant was similar to that observed in an $a \lg T^{-}$ mutant, a regulatory gene of the alginate biosynthetic cluster in P. syringae (Keith and Bender 1999). Alginate has been postulated to facilitate the colonization or dissemination in planta of $P$. syringae because its production is associated with increased epiphytic fitness (Yu et al. 1999) and resistance to desiccation and toxic molecules (Keith and Bender 1999). Therefore, the limited survival of an $a e f R^{-}$and an $a h l I^{-} a h l R^{-}$double mutant on dry leaves (Quiñones et al. 2004), may be due, in part, to the reduced production of alginate in these mutant strains.

Motility also is considered an important epiphytic fitness trait in $P$. syringae $\mathrm{B} 728 \mathrm{a}$, enabling cells to locate resources and to access sites that allow them to avoid environmental stresses (Haefele and Lindow 1987; Lindow et al. 1993). Swarming is thought to be a ubiquitous form of motility among eubacteria (Harshey 1994) and is an intrinsically surface-linked and celldensity-dependent phenomenon (Eberl et al. 1999). Bacteria displaying swarming motility propagate on semisolid surfaces in a coordinated and social manner (Eberl et al. 1999). AHL-dependent gene regulation is required for swarming motility in $P$. aeruginosa and Serratia liquefaciens by promoting the synthesis of biosurfactants that facilitate the spreading of bacteria on the surface (Köhler et al. 2000; Lindum et al. 1998). Although a previous study reported that swarming motility in $P$. syringae B728a was not abolished in an ahl mutant (Kinscherf and Willis 1999), the present study provides compelling evidence for the role of both the AhlI-AhlR quorum-sensing system and AefR in the regulation of swarming motility. Both an aefR $R^{-}$mutant and an $a h l I^{-} a h l R^{-}$double mutant were hypermotile under conditions when the wild-type cells displayed little movement (Fig. 1). Under such conditions, an $a e f R^{-}$mutant moved 5.6-fold more and an $a h l I^{-} a h l R^{-}$double mutant moved 2.3-fold more than the wild-type strain (Table 2). Therefore, quorum sensing

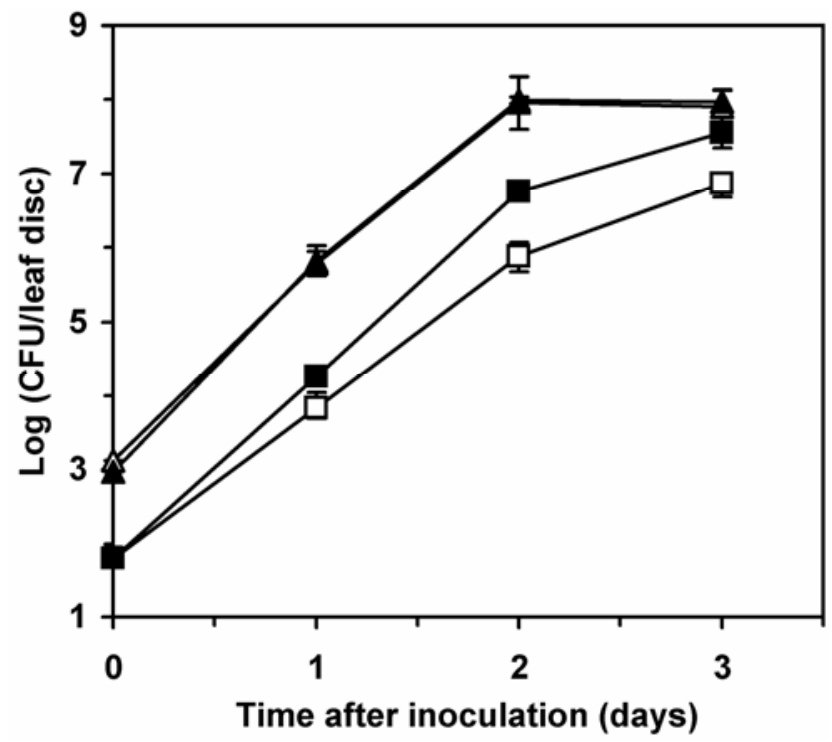

Fig. 8. Population sizes of Pseudomonas syringae pv. tabaci within $N$-acyl homoserine lactone (AHL)-producing and wild-type tobacco plants. AHLproducing transgenic (open symbols) or wild-type (closed symbols) tobacco plants were infiltrated with a $P$. syringae pv. tabaci $11528 \mathrm{R}$ cell suspension that contained either $1 \times 10^{5} \mathrm{CFU} / \mathrm{ml}$ (triangles) or $1 \times 10^{3} \mathrm{CFU} / \mathrm{ml}$ (squares). Results presented are from a single representative experiment with 10 replicates. Vertical bars represent the standard error of the mean of $\log _{10}$-transformed bacterial population sizes. downregulates swarming motility when the population is at relatively lower cell densities.

The enhanced swarming motility of the quorum-sensing mutants was observed in two separate scenarios. First, although both mutants moved faster than the parental strain, the aefR ${ }^{-}$ mutant strain appeared to be the most hypermotile because it also started to swarm at an earlier time (Fig. 2). These findings indicate that AefR, a regulator of autoinduction that is expressed even during low cell densities (Quiñones et al. 2004), plays a more important role in suppressing swarming motility at early stages of quorum sensing. It is noteworthy that the quorum-sensing system in Yersinia pseudotuberculosis has a negative effect in swarming motility (Atkinson et al. 1999); mutants in either the AHL synthase gene, yspI, or in the AHL regulator gene, $y s p R$, were hypermotile. It is tempting to speculate that a common feature in the lifestyle in both of these bacterial pathogens may have selected for suppression of swarming motility. One possible explanation for this type of negative regulation in $P$. syringae would apply if nutrients are relatively localized on leaves and epiphytes prosper primarily at the sites of nutrient release (Leveau and Lindow 2001, 2002; Lindow and Brandl 2003). In that case, it would be beneficial for immigrant bacteria to a leaf to be motile, enabling them to explore the leaf surface for sites of nutrient release. Upon reaching such sites, multiplication to large population sizes in cell aggregates would occur, and further motility on the leaf would seem to be detrimental to such cells. Sites away from cell aggregates would be expected to be lower in resource abundance as well as AHL signals. Therefore, AHL-mediated suppression of swarming would tend to inhibit bacterial movement away from high-nutrient sites while promoting resource acquisition at earlier stages of leaf colonization. Presumably, Y. pseudotuberculosis also exploits localized sites of infection (Logsdon and Mecsas 2003). In the second scenario, when swarming motility was examined at higher inoculum concentrations, the differences in swarming motility between the quorum-sensing mutants and the wild-type strain were subtle, with the wildtype strain being more motile than at lower cell concentrations.

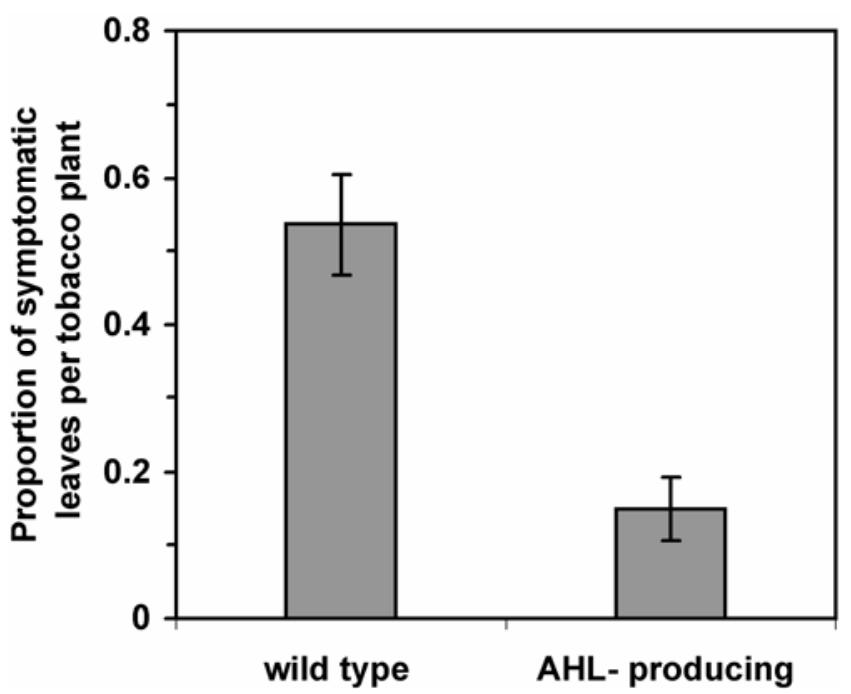

Fig. 9. Incidence of disease symptoms on leaves of $N$-acyl homoserine lactone (AHL)-producing and wild-type tobacco incited by Pseudomonas syringae pv. tabaci after surface inoculation. Tobacco leaves were spray inoculated with a $P$. syringae pv. tabaci $11528 \mathrm{R}$ cell suspension containing $1 \times 10^{6} \mathrm{CFU} / \mathrm{ml}$ and incubated under moist conditions at $28^{\circ} \mathrm{C}$ for 14 days. Results presented are from a single representative experiment that consisted of 10 replicates per treatment, and the mean difference $(P=$ 0.003 ) was determined by a Student's $t$ test. Vertical bars represent the standard error of the mean of leaves infected per plant. 
It is possible that, at this growth stage, a separate regulatory mechanism with a more pronounced effect, one mediated by GacA, then would control swarming motility (Kinscherf and Willis 1999).

Previous studies have demonstrated that swarming motility may facilitate the entry of $P$. syringae into leaves. The movement of $P$. syringae on the surface of bean leaves has been shown to be assisted by flagellar motility and to require high relative humidity or moisture (Leben et al. 1970; Panopoulos and Schroth 1974). Flagellar mutants of P. syringae were remarkably impaired in their infection potential, presumably due to their inability to enter into the leaf tissue through stomates (Hattermann and Ries 1989; Panopoulos and Schroth 1974). Furthermore, flagellar motility contributed to the epiphytic fitness of $P$. syringae by allowing it to establish large, stable epiphytic populations and to survive environmental stress (Haefele and Lindow 1987; Lindow et al. 1993). In the present study, we investigated whether epiphytic populations of the hypermotile AHL-deficient mutants also would show an enhanced ability to access areas that were protected from hydrogen peroxide killing and to infect leaves. Intriguingly, both an aefR ${ }^{-}$mutant and an $a h l I^{-} a h l R^{-}$double mutant achieved higher internal population sizes when compared with wild-type cells when measured soon after inoculation (Fig. 3). The internal population sizes of all strains increased with time, but the AHL-deficient mutants were always more numerous within the leaves, especially at earlier time points. A direct correlation between hypermotility and an increased incidence of disease also was observed. When incubated on moist bean leaves for $48 \mathrm{~h}$, both an $a e f R^{-}$mutant and an $a h l I^{-} a h l R^{-}$double mutant incited a much higher number of lesions on bean leaves than the wild type (Fig. 4). Interestingly, an aefR $R^{-}$mutant, which displayed hypermotility in culture, was also the most virulent. In contrast, when strains were provided only a short and humid incubation period $(24 \mathrm{~h})$, there were no significant differences in the number of lesions caused by the wild-type and AHL-deficient mutants (Fig. 4). It is possible that, under the conditions used in this study, at least two different infection processes may be occurring on a leaf after inoculation with a relatively few cells of $P$. syringae. Under moist conditions, a rapid multiplication of $P$. syringae occurs on leaves for $24 \mathrm{~h}$. However, when the leaf surfaces are subsequently allowed to dry, further epiphytic growth ceases and some of epiphytic cells succumb to desiccation stress (Beattie and Lindow 1994). As epiphytic populations increase in size, some cells gain entrance to the intercellular spaces on the leaf, where the infection process can be initiated (Beattie and Lindow 1999; Wilson et al. 1999). In the present study, when cells were provided ample time (48 h) for both multiplication and motility on leaves, the hypermotile cells of the AHL-deficient mutants presumably entered the leaf in larger numbers than the wild-type strain and, therefore, had a higher likelihood of initiating a successful infection. Our previous findings showed that the epiphytic populations of the AHL-deficient mutants are less tolerant to desiccation stress (Quiñones et al. 2004). Therefore, when the plants were allowed to dry after only a short (24-h) moist period, the epiphytic population of the AHL-deficient mutants may have preferentially succumbed relative to that of the wild-type strain before invasion of the leaf could occur. The increased mobility of the AHL-deficient mutants may have been offset by their lower tolerance to desiccation stress, resulting in similar numbers of infections when provided a limited time for invasion of leaves before stressful conditions were imposed.

AHL-mediated quorum sensing affected various stages of symptom development during plant infection. $P$. syringae B728a causes lesions on both pods and leaves (Hirano and Upper 2000) and, during the early stages of lesion formation on pods, water-soaked lesions result from the release of fluid from the plant tissue (Hirano and Upper 2000; Willis et al. 1990). AefR and the AhlI-AhlR quorum-sensing system appear to differentially regulate traits involved in the formation of water-soaked lesions on pods. An $a e f R^{-}$mutant produced watersoaked lesions that were $41 \%$ smaller, while an $a h l I^{-} a h l R^{-}$ double mutant produced lesions that were $20 \%$ larger than those incited by the wild type (Fig. 5). Therefore, $P$. syringae seems to employ different regulatory pathways leading to the formation of water-soaked lesions. In contrast to the wild type, none of the AHL-deficient mutants incited any internal tissue maceration of bean pods (Fig. 6). AHL-mediated regulation of traits responsible for the maceration of plant tissue has been implicated in the virulence of other plant-pathogenic bacteria. For example, quorum sensing in E. caratovora is required for the production of exoenzymes such as cellulases, pectin lyase, pectate lyase, polygalacturonase, and proteases that lead to tissue maceration (Jones et al. 1993; Pirhonen et al. 1993). Tissue maceration caused by the wild-type strain is evident only 4 days or more after inoculation; therefore, tissue maceration is a later stage of infection than water soaking. Thus, an AhlIAhlR quorum-sensing system and AefR in $P$. syringae are involved in both early and late stages of disease development. This quorum-sensing regulation in $P$. syringae during various stages of plant infection appears to be a different strategy than that used by another plant pathogen, E. carotovora subsp. atroseptica. The AHL-mediated quorum sensing in E. carotovora subsp. atroseptica regulates only traits required for later stages of host plant infection and not initial plant colonization (Smadja et al. 2004).

Several regulatory genes affect quorum sensing as well as other traits in $P$. syringae; therefore, the different observed phenotypes in an aefR ${ }^{-}$mutant, a $g a c A^{-}$mutant, and an $a h l I^{-}$ $a h l R^{-}$double mutant can be explained. Our previous findings suggested that AefR and GacA play an indirect role in the regulation of quorum sensing because the defect in ahlI transcription in either an $a e f R^{-}$or a $g a c A^{-}$mutant can be overcome by exogenous AHL (Quiñones et al. 2004). In addition to regulating AHL production, the regulators AefR and GacA may directly control other traits via separate regulatory cascades. For example, the regulation of AHL production by GacA occurs via a different pathway from the one involved in syringomycin and protease production and lesion formation on bean leaves (Kinscherf and Willis 1999; Kitten et al. 1998). Given that AefR and GacA are separate regulators that independently modulate quorum sensing (Quiñones et al. 2004), one would expect a difference in the expression of other traits such as EPS production, motility, and virulence between an $a e f R^{-}$and a $g a c A^{-}$mutant. Distinct phenotypes also were observed between an $a e f R^{-}$mutant and an $a h l I^{-} a h l R^{-}$double mutant when examined for water-soaking lesion development. Our previous findings demonstrated that aefR is expressed even at low cell densities and that the defect in AHL production in an aef $R^{-}$mutant was more pronounced at earlier stages of growth (Quiñones et al. 2004). Therefore, it is possible that AefR may play an important role in the expression of early disease symptoms, such as water soaking, during the infection process and may account for the reduced lesions that were observed in an aef $R^{-}$mutant. Clearly, additional studies are needed to further characterize the interaction between the AhlI-AhlR quorum-sensing system and the regulators AefR and GacA.

Given that quorum sensing regulated virulence of $P$. syringae B728a on bean, we explored whether it was possible to alter $P$. syringae's ability to cause disease by expressing AHL in plants. This question was addressed by employing transgenic tobacco plants that were engineered to express the yenI gene of $Y$. enterocolitica, resulting in the synthesis of 3-oxo-C6-HSL 
and hexanoyl homoserine lactone (C6-HSL) (Fray et al. 1999). The AHLs are produced in both plant roots and leaves and are easily detected on the leaf surface by various AHL-biosensor strains (Fray et al. 1999). Tobacco is not a normal host for $P$. syringae pv. syringae; therefore, we assessed the virulence of $P$. syringae pv. tabaci in AHL-producing tobacco. $P$. syringae pv. tabaci responds to 3-oxo-C6-HSL (Shaw et al. 1997), and the genes encoding the AHL synthase and AHL regulator show $89 \%$ sequence identity to strain B728a (Quiñones et al. 2004), suggesting that these pathovars share a similar quorum-sensing system. The expression of AHL in transgenic tobacco altered the process of disease caused by $P$. syringae pv. tabaci. When $P$. syringae pv. tabaci was infiltrated directly into leaves, the severity of disease in the AHL-producing plants was decreased when compared with wild-type tobacco. Interestingly, the differences in disease severity between wild-type and AHL-producing tobacco were less pronounced with increasing numbers of cells of $P$. syringae pv. tabaci infiltrated into the plant. Obvious differences in disease were observed when $10^{5} \mathrm{CFU} / \mathrm{ml}$ was infiltrated, and a more pathogen-resistant phenotype was observed when $10^{3} \mathrm{CFU} / \mathrm{ml}$ were infiltrated. Less-apparent differences in symptom severity were observed at $10^{7}$ and $10^{9}$ CFU/ml (Fig. 7). Likewise, the multiplication of $P$. syringae pv. tabaci was suppressed significantly when inoculated into AHL-producing tobacco, but only when low inoculum concentrations were used (Fig. 8). The observation of reduced disease severity and bacterial growth following inoculation with low but not high levels of inoculum was similar to that observed when E. carotovora also was inoculated into AHL-producing tobacco (Mäe et al. 2001).

As proposed by Mäe and collaborators, AHL production by the transgenic plant could induce the expression of bacterial virulence traits even when the pathogen cells were at sufficiently low population sizes in the plant. This early expression of the bacterial virulence traits was hypothesized to enable recognition of the previously "stealth" pathogen by the plant and, hence, initiate a successful defense reaction in the plant (Alfano and Collmer 1996; Mäe et al. 2001). However, when relatively large numbers of bacterial cells are inoculated into plants, the pathogen would already be present in sufficient numbers to overwhelm plant defenses and trigger gene expression of virulence factors that would result in disease. In this situation, the AHL signal produced by the transgenic plant would not noticeably alter the normal pattern of virulence gene expression because the large number of bacteria would already be producing their own high levels of AHL. Although P. syringae and E. carotovora differ greatly in the types of symptoms that they induce in plants, it appears that they both share a similar population size-dependent regulation of virulence genes and, therefore, a similar "stealth-style" of pathogenesis. The production of AHL in tobacco clearly altered the normal pattern of disease and was effective in controlling bacterial multiplication, particu- larly when the populations of the pathogen were small. However, a recent study reported that production of AHL in potato plants resulted in an increased disease incidence in E. carotovora subsp. atroseptica at low inoculum levels (Toth et al. 2004). It is possible that the induction of plant defenses in these transgenic potato plants may initially be retarded or in some way reduced by the pathogen, allowing a successful infection to occur (Toth et al. 2004).

The incidence of infection in AHL-producing tobacco also was greatly reduced when infection resulted from an epiphytic inoculum. In this more natural disease process, a variety of bacterial traits that contribute to infection would be operating, unlike when inoculum was infiltrated directly into leaves. When compared with the wild-type plants, AHL-producing tobacco had 3.6-fold fewer diseased leaves (Fig. 9). To our knowledge, this is the first evidence that foliar disease occurring by a natural infection process can be suppressed by expressing AHL in plants. There are two possible explanations for the reduction in lesion formation in AHL-producing plants. After surface inoculation on the transgenic plant, most of the $P$. syringae pv. tabaci cells probably occurred as solitary cells or in small groups that normally would not have led to AHL production. These cells probably encountered high concentrations of AHL produced on the leaf surface of the transgenic plant. Presumably, this would result in an early expression of traits that normally occur only during later stages of colonization. Therefore, the AHL might have caused repression in motility when the epiphytic population of $P$. syringae pv. tabaci was at a relatively low cell density, resulting in an inefficient invasion into the leaf. As an alternative explanation, premature expression of virulence traits by $P$. syringae pv. tabaci cells that had entered the plant may have allowed the plant cells to recognize and halt the pathogen in sites that it had invaded, while still at low population sizes. Thus, expression of AHL signals in plants appears to be an efficient strategy for preventing disease caused by foliar pathogens such as $P$. syringae. Further work will be necessary, involving a plant host that produces AHL and also is compatible with $P$. syringae pv. syringae to assess whether these observations apply to all pathovars of $P$. syringae.

Although we only described a few phenotypes, this study suggests that AHL-regulated traits in P. syringae are important in its interaction with the plant host. A genomic analysis of quorum-sensing-regulated traits should provide more insights into the processes of epiphytic growth, survival, and virulence.

\section{MATERIALS AND METHODS}

\section{Bacterial strains and growth conditions.}

The bacterial strains and plasmids that were used in this study are described in Table 3 . The source and characteristics of $P$. syringae pv. syringae $\mathrm{B} 728 \mathrm{a}$, a pathogen of bean, have

Table 3. Bacterial strains and plasmids used in this study

\begin{tabular}{|c|c|c|}
\hline Strain, plasmid & Relevant characteristics $^{\mathrm{z}}$ & Reference or source \\
\hline \multicolumn{3}{|l|}{ Pseudomonas syringae pv. syringae } \\
\hline B728a & $\mathrm{Rf}^{\mathrm{T}}$, wild type, bean pathogen & Loper and Lindow 1987 \\
\hline 538 & $\mathrm{Rf}^{\mathrm{T}} \mathrm{Km}^{\mathrm{r}}, \Delta$ aefR::Tn5, B728a derivative & Quiñones et al. 2004 \\
\hline A9 & $\mathrm{Rf}^{\mathrm{r}} \mathrm{Km}^{\mathrm{r}}, \Delta$ ahlI-ahlR::Kan, B728a derivative & Quiñones et al. 2004 \\
\hline BGACX & $\mathrm{Rf}^{\mathrm{T}} \mathrm{Km}^{\mathrm{r}}, \Delta g a c A:: \mathrm{Kan}, \mathrm{B} 728$ a derivative & Rich et al. 1994 \\
\hline NPS3136 & $\mathrm{Rf}^{\mathrm{r}} \mathrm{Km}^{\mathrm{r}}, \Delta$ gac $S:$ Kan, B728a derivative & Willis et al. 1990 \\
\hline P. syringae pv. Tabaci $11528 \mathrm{R}$ & $\mathrm{Rf}^{\mathrm{T}}$, wild type, tobacco pathogen & B. Staskawicz, University of California-Berkeley \\
\hline Agrobacterium tumefaciens NTI & 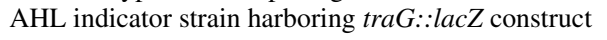 & Piper et al. 1993 \\
\hline \multicolumn{3}{|l|}{ Plasmids } \\
\hline pSVB33 & $\mathrm{Km}^{\mathrm{r}}, \operatorname{traR+}$ & Piper et al. 1993 \\
\hline pJM749 & $\mathrm{Cb}^{\mathrm{r}}$, contains a traG::lacZ gene fusion & Piper et al. 1993 \\
\hline
\end{tabular}

${ }^{\mathrm{z}} \mathrm{AHL}=\mathrm{N}$-acyl homoserine lactone, $\mathrm{Rf}=$ rifampicin, $\mathrm{Km}=$ kanamycin, $\mathrm{Cb}=$ carbenicillin, and $\mathrm{r}=$ resistance. 
been described previously (Loper and Lindow 1987). P. syringae strains were grown at $28^{\circ} \mathrm{C}$ in King's B agar (KB) (King et al. 1954), King's B broth (KBB), or MGY (Keane et al. 1970). The following concentrations of antibiotics were used: carbenicillin, $100 \mu \mathrm{g} / \mathrm{ml}$; kanamycin, $50 \mu \mathrm{g} / \mathrm{ml}$; and rifampicin, 100 $\mu \mathrm{g} / \mathrm{ml}$.

\section{Alginate production.}

$P$. syringae strains were grown for 2 days on $\mathrm{KB}$ amended with the appropriate antibiotics. Single colonies then were streaked on MGY containing 0.6 M sorbitol and grown for 3 days at $28^{\circ} \mathrm{C}$ to promote maximal levels of alginate production, as in previous studies (Keith and Bender 1999; Willis et al. 2001). Cells were removed from plates and resuspended in $0.9 \% \mathrm{NaCl}$ as described previously (May and Chakrabarty 1994). The alginate was separated from the bacterial cells by centrifugation at $13,000 \times g$ for $20 \mathrm{~min}$ and further quantified by a modified carbazol assay (May and Chakrabarty 1994). Total cellular protein was determined by a Bradford protein assay (Bio-Rad Protein Assay; Bio-Rad, Hercules, CA, U.S.A.). The concentration of the isolated alginate from three replicates was determined from a standard curve of alginic acid from Macrocystis pyrifera (Sigma-Aldrich, St. Louis) and reported as micrograms of alginate per milligram of total cellular protein.

\section{Susceptibility to ROIs.}

To determine the susceptibility to ROIs, $P$. syringae strains were grown on $\mathrm{KB}$ for 2 days, removed from plates, and resuspended in $10 \mathrm{mM}$ potassium phosphate buffer, $\mathrm{pH} 7.0$ (PB). Cells were then mixed with $\mathrm{KBB}$ containing $0.6 \%$ melted agar to a final concentration of $5 \times 10^{8} \mathrm{CFU} / \mathrm{ml}$, and 2 $\mathrm{ml}$ of this suspension was overlaid on a KB plate. Once the overlay had solidified, a filter disc (Fisherbrand, Grade P8Creped, $6 \mathrm{~mm}$ in diameter) containing 3\% hydrogen peroxide was placed in the center of each plate and the plates were incubated at $28^{\circ} \mathrm{C}$ for $18 \mathrm{~h}$. The susceptibility to killing by hydrogen peroxide was determined by measuring the diameter of the zone of inhibited growth surrounding the filters, as in previous studies (Keith and Bender 1999). Each treatment consisted of five replicates and six measurements were taken for each replicate.

\section{Motility assays.}

Swarming motility was assessed on semisolid KB plates that contained $0.4 \%$ agar, as in previous studies (Kinscherf and Willis 1999). Cells first were grown on KB for 2 days, and then rinsed and resuspended in PB. Filter discs (Fisherbrand, Grade P8-Creped, $6 \mathrm{~mm}$ in diameter) were placed in the center of the plate and inoculated with a drop containing either $1 \times$ $10^{7}$ or $1 \times 10^{9}$ cells. Plates then were incubated at $26^{\circ} \mathrm{C}$. The radius of swarming of the cells to the edge of the filter discs was measured at various times. Measurements of colony diameter were made, and the experiments were repeated several times, each with three replicates.

To determine the ability of $P$. syringae strains to enter the interior of leaves, 2-week-old bean plants (Phaseolus vulgaris cv. Bush Blue Lake 274, containing 8 to 10 seedlings per pot) having fully expanded trifoliate leaves were spray inoculated with a suspension containing $10^{6} \mathrm{CFU} / \mathrm{ml}$ in PB. Three pots were inoculated for each strain. At various times, three trifoliate leaves were removed randomly and surface sterilized with $15 \%$ hydrogen peroxide for $10 \mathrm{~min}$, as in previous studies (Wilson et al. 1999), followed by a treatment with catalase at $7.5 \mu \mathrm{g} / \mathrm{ml}$ for $10 \mathrm{~min}$. Leaves then were macerated in $5 \mathrm{ml}$ of $\mathrm{PB}$, and serial dilutions of each sample were plated on $\mathrm{KB}$ containing rifampicin plus $12.5 \mu \mathrm{g}$ of benomyl per ml, using a spiral diluter/plater (Spiral Systems, Inc. Cincinnati, OH, U.S.A.).

\section{Inoculation of bean plants.}

Cells of $P$. syringae strains were grown on $\mathrm{KB}$ for 2 days at $28^{\circ} \mathrm{C}$, removed from plates, resuspended in $\mathrm{PB}$, and diluted into $1 \mathrm{mM}$ potassium phosphate buffer to yield a final concentration of $10^{6} \mathrm{CFU} / \mathrm{ml}$ (Quiñones et al. 2004; Wilson et al. 1999). Bean plants with fully expanded primary and trifoliate leaves were spray inoculated with the cell suspensions and then placed in a humid chamber maintained at nearly $100 \%$ relative humidity $(\mathrm{RH})$ at $28^{\circ} \mathrm{C}$. After either 24 or $48 \mathrm{~h}$, plants were transferred to a greenhouse bench $(<50 \% \mathrm{RH})$ and allowed to develop disease symptoms for 7 to 8 days. The numbers of visible brown spot lesions were counted on trifoliate leaves (six leaves per plants; three pots per treatment) that were fully expanded at the time of inoculation. To determine the population sizes of epiphytic bacteria at various times during the inoculation process, four trifoliate leaves were removed randomly from plants at a given time, and each leaf was immersed individually in $20 \mathrm{ml}$ of washing buffer (100 mM potassium phosphate buffer containing $0.1 \%$ Bacto-peptone) (Difco Laboratories, Detroit) in 25-mm-diameter test tubes. The tubes then were sonicated in an ultrasonic bath for $7 \mathrm{~min}$ and vortexed briefly, as previously described (Quiñones et al. 2004). Serial dilutions of each sample were plated on $\mathrm{KB}$ containing rifampicin plus $12.5 \mu \mathrm{g}$ of benomyl per $\mathrm{ml}$ as above.

Virulence on wounded bean pods was assessed by placing a droplet of cells $\left(10^{8}\right.$ cells in PB) on the site of a 1-mm incision made with a razor blade to three sites on each 10-day-old, excised bean pod (Phaseolus vulgaris cv. Bush Blue Lake 274). Pods then were incubated for 3 to 4 days under humid conditions at $28^{\circ} \mathrm{C}$. Disease symptoms were quantified by measuring the diameter of water-soaked lesions perpendicular to the razor wound. Longitudinal sections of the pods also were made to examine internal tissue maceration.

\section{Inoculation of tobacco plants.}

The growth and pathogenicity of Pseudomonas syringae pv. tabaci was investigated in wild-type tobacco (Nicotiana tabacum L. cv. Samsun) and transgenic plants expressing yenI from $Y$. enterocolitica and producing 3-oxo-C6-HSL and C6HSL (Fray et al. 1999). The production of the AHL was confirmed by testing leaf discs (6 $\mathrm{mm}$ in diameter) in a bioassay similar to that previously described (Quiñones et al. 2004) by using Agrobacterium tumefaciens NT1 (pSVB33, pJM749) as the AHL indicator strain. To examine the growth of $P$. syringae pv. tabaci within plants, cells were grown on $\mathrm{KB}$ for 2 days, removed from plates, and resuspended in PB. Bacterial suspensions of various cell concentrations were infiltrated through a small incision into the apoplast of tobacco leaf tissue using a 1-ml needleless syringe. Immediately after infiltration, plants were incubated under moist conditions $(100 \% \mathrm{RH})$ in a humid chamber at $28^{\circ} \mathrm{C}$ with $14 \mathrm{~h}$ of light/day. Plants were evaluated daily for disease symptoms. To determine the population sizes of bacteria within leaves, 1.5 -cm-diameter leaf discs (10 leaf discs per treatment) were excised randomly from the inoculated areas of each leaf and macerated in PB. Serial dilutions of each sample were plated on $\mathrm{KB}$ containing rifampicin plus $21.6 \mu \mathrm{g}$ of natamycin per $\mathrm{ml}$ as above. To examine the incidence of foliar infections caused by topically applied $P$. syringae pv. tabaci, leaves of AHL-producing and control tobacco plants were spray inoculated to wetness with a suspension containing $10^{7} \mathrm{CFU} / \mathrm{ml}$ diluted in $1 \mathrm{mM}$ potassium phosphate buffer. After inoculation, plants were placed in a humid chamber, and the number of leaves displaying disease symptoms was assessed after 14 days. 


\section{Statistical analysis.}

Descriptive statistical analysis, Student's $t$ test, Duncan's multiple test range, and Bonferroni's means comparison test were performed with Microsoft Excel 2000 (Microsoft Co., Redmond, WA), Systat (version 10.2; Systat Software, Inc., Point Richmond, CA), or SAS Software (version 6.03; SAS Institute Inc., Cary, NC, U.S.A.).

\section{ACKNOWLEDGMENTS}

We thank R. G. Fray from the School of Biological Sciences at Nottingham University in Loughborough, U. K. for generously providing the wild-type and AHL-producing transgenic tobacco and G. Wichman and S. Blitch for critically reviewing the manuscript. This work was supported by a United States Department of Agriculture-CREES, National Research Initiative Competitive Grant 2003-01132 to S. E. Lindow, by a Ford Foundation Postdoctoral Fellowship to B. Quiñones, and by a United States Environmental Protection Agency-STAR Graduate Fellowship to G. Dulla.

\section{LITERATURE CITED}

Alfano, J. R., and Collmer, A. 1996. Bacterial pathogens in plants: Life up against the wall. Plant Cell 8:1683-1698.

Atkinson, S., Throup, J. P., Stewart, G. S. A. B., and Williams, P. 1999. A hierarchical quorum-sensing system in Yersinia pseudotuberculosis is involved in the regulation of motility and clumping. Mol. Microbiol. 33:1267-1277.

Beattie, G. A., and Lindow, S. E. 1994. Comparison of the behavior of epiphytic fitness mutants of Pseudomonas syringae under controlled and field conditions. Appl. Environ. Microbiol. 60:3799-3808.

Beattie, G. A., and Lindow, S. E. 1999. Bacterial colonization of leaves: A spectrum of strategies. Phytopathology 89:353-359.

Beck von Bodman, S., and Farrand, S. K. 1995. Capsular polysaccharide biosynthesis and pathogenicity in Erwinia stewartii require induction by an $N$-acylhomoserine lactone autoinducer. J. Bacteriol. 177:5000-5008.

Beck von Bodman, S., Majerczak, D. R., and Coplin, D. L. 1998. A negative regulator mediates quorum-sensing control of exopolysaccharide production in Pantoea stewartii subsp. stewartii. Proc. Natl. Acad. Sci. U.S.A. 95:7687-7692.

Dumenyo, C. K., Mukherjee, A., Chun, W., and Chatterjee, A. K. 1998. Genetic and physiological evidence for the production of $N$-acyl homoserine lactones by Pseudomonas syringae pv. syringae and other fluorescent plant pathogenic Pseudomonas species. Eur. J. Plant Pathol. 104:569-582.

Dye, D. W., Bradbury, J. F., Goto, M., Hayward, A. C., Lelliott, R. A., and Schroth, M. N. 1980. International standards for naming pathovars of phytopathogenic bacteria and a list of pathovar names and pathotype strains. Rev. Plant Pathol. 59:153-168.

Eberl, L., Molin, S., and Givskov, M. 1999. Surface motility of Serratia liquefaciens MG1. J. Bacteriol. 181:1703-1712.

Farr, S. B., and Kogoma, T. 1991. Oxidative stress responses in Escherichia coli and Salmonella typhimurium. Microbiol. Rev. 55:561-585.

Fray, R. G. 2001. Plants genetically modified to produce $N$-acylhomoserine lactones signal to bacteria. (Abstr.) Phytopathology 91:S160.

Fray, R. G., Throup, J. P., Daykin, M., Wallace, A., Williams, P., Stewart, G. S., and Grierson, D. 1999. Plants genetically modified to produce $N$ acylhomoserine lactones communicate with bacteria. Nat. Biotechnol. 17:1017-1020.

Haefele, D. M., and Lindow, S. E. 1987. Flagellar motility confers epiphytic fitness advantages upon Pseudomonas syringae. Appl. Environ. Microbiol. 53:2528-2533.

Harshey, R. M. 1994. Bees aren't the only ones: swarming in gram-negative bacteria. Mol. Microbiol. 13:389-394.

Hattermann, D. R., and Ries, S. M. 1989. Motility of Pseudomonas syringae pv. glycinea and its role in infection. Phytopathology 79:284-289.

Hirano, S. S., and Upper, C. D. 2000. Bacteria in the leaf ecosystem with emphasis on Pseudomonas syringae: A pathogen, ice nucleus, and epiphyte. Microbiol. Mol. Biol. Rev. 64:624-653.

Jones, S., Yu, B., Bainton, N. J., Birdsall, M., Bycroft, B. W., Chhabra, S. R., Cox, A. J., Golby, P., Reeves, P. J., and Stephens, S., Winson, M. K., Salmond, G. P. C., and Williams, P. 1993. The lux autoinducer regulates the production of exoenzyme virulence determinants in Erwinia carotovora and Pseudomonas aeruginosa. EMBO (Eur. Mol. Biol. Organ.) J. $12: 2477-2482$.

Keane, P. J., Kerr, A., and New, P. B. 1970. Crown gall of stone fruit. II. Identification and nomenclature of Agrobacterium Isolates. Aust. J. Biol. Sci. 23:585-595.
Keith, L. M., and Bender, C. L. 1999. AlgT (sigma22) controls alginate production and tolerance to environmental stress in Pseudomonas syringae. J. Bacteriol. 181:7176-7184.

King, E. O., Ward, M. K., and Raney, D. E. 1954. Two simple media for the demonstration of pyocyanin and fluorescein. J. Lab. Clin. Med. 44:310-307.

Kinscherf, T. G., and Willis, D. K. 1999. Swarming by Pseudomonas syringae $\mathrm{B} 728$ a requires gacS (lemA) and gacA but not the acyl-homoserine lactone biosynthetic gene ahlI. J. Bacteriol. 181:4133-4136.

Kitten, T., Kinscherf, T. G., McEvoy, J. L., and Willis, D. K. 1998. A newly identified regulator is required for virulence and toxin production in Pseudomonas syringae. Mol. Microbiol. 28:917-929.

Köhler, T., Curty, L. K., Barja, F., van Delden, C., and Pechere, J. C. 2000. Swarming of Pseudomonas aeruginosa is dependent on cell-tocell signaling and requires flagella and pili. J. Bacteriol. 182:59905996.

Leben, C., Schroth, M. N., and Hildebra, D. C. 1970. Colonization and movement of Pseudomonas syringae on healthy bean seedlings. Phytopathology 60:677-680.

Leveau, J. H., and Lindow, S. E. 2002. Bioreporters in microbial ecology. Curr. Opin. Microbiol. 5:259-265.

Leveau, J. H. J., and Lindow, S. E. 2001. Appetite of an epiphyte: Quantitative monitoring of bacterial sugar consumption in the phyllosphere. Proc. Natl. Acad. Sci. U.S.A. 98:3446-3453.

Lindow, S. E., Andersen, G., and Beattie, G. A. 1993. Characteristics of insertional mutants of Pseudomonas syringae with reduced epiphytic fitness. Appl. Environ. Microbiol. 59:1593-1601.

Lindow, S. E., and Brandl, M. T. 2003. Microbiology of the phyllosphere. Appl. Environ. Microbiol. 69:1875-1883.

Lindum, P. W., Anthoni, U., Christophersen, C., Eberl, L., Molin, S., and Givskov, M. 1998. $N$-acyl-L-homoserine lactone autoinducers control production of an extracellular lipopeptide biosurfactant required for swarming motility of Serratia liquefaciens MG1. J. Bacteriol. 180:6384-6388.

Logsdon, L. K., and Mecsas, J. 2003. Requirement of the Yersinia pseudotuberculosis effectors YopH and YopE in colonization and persistence in intestinal and lymph tissues. Infect. Immun. 71:4595-4607.

Loh, J., Pierson, E. A., Pierson, L. S., 3rd, Stacey, G., and Chatterjee, A. 2002. Quorum sensing in plant-associated bacteria. Curr. Opin. Plant Biol. 5:285-290.

Loper, J. E., and Lindow, S. E. 1987. Lack of evidence for in situ fluorescent pigment production by Pseudomonas syringae pv. syringae on bean leaf surfaces. Phytopathology 77:1449-1454.

Mäe, A., Montesano, M., Koiv, V., and Palva, E. T. 2001. Transgenic plants producing the bacterial pheromone $N$-acyl-homoserine lactone exhibit enhanced resistance to the bacterial phytopathogen Erwinia carotovora. Mol. Plant-Microbe Interact. 14:1035-1042.

May, T. B., and Chakrabarty, A. M. 1994. Isolation and assay of Pseudomonas aeruginosa alginate. Methods Enzymol. 235:295-304.

Monier, J.-M., and Lindow, S. E. 2003. Differential survival of solitary and aggregated bacterial cells promotes aggregate formation of leaf surfaces. Proc. Natl. Acad. Sci. U.S.A. 100:15977-15982.

Monier, J.-M., and Lindow, S. E. 2004. Frequency, size and localization of bacterial aggregates on bean leaf surfaces. Appl. Environ. Microbiol. 70:346-355.

Panopoulos, N. J., and Schroth, M. N. 1974. Role of flagellar motility in invasion of bean leaves by Pseudomonas phaseolicola. Phytopathology 64:1389-1397.

Peñaloza-Vázquez, A., Kidambi, S. P., Chakrabarty, A. M., and Bender, C. L. 1997. Characterization of the alginate biosynthetic gene cluster in Pseudomonas syringae pv. syringae. J. Bacteriol. 179:4464-4472.

Piper, K. R., Beck von Bodman, S., and Farrand, S. K. 1993. Conjugation factor of Agrobacterium tumefaciens regulates Ti plasmid transfer by autoinduction. Nature 362:448-450.

Pirhonen, M., Flego, D., Heikinheimo, R., and Palva, E. T. 1993. A small diffusible signal molecule is responsible for the global control of virulence and exoenzyme production in the plant pathogen Erwinia carotovora. EMBO (Eur. Mol. Biol. Organ.) J. 12:2467-2476.

Quiñones, B., Pujol, C. J., and Lindow, S. E. 2004. Regulation of AHL production and its contribution to epiphytic fitness in Pseudomonas syringae. Mol. Plant-Microbe Interact. 17:521-531.

Rich, J. J., Kinscherf, T. G., Kitten, T., and Willis, D. K. 1994. Genetic evidence that the gacA gene encodes the cognate response regulator for the lemA sensor in Pseudomonas syringae. J. Bacteriol. 176:7468-7475.

Rouse, D. I., Nordheim, E. V., Hirano, S. S., and Upper, C. D. 1985. A model relating the probability of foliar disease incidence to the population frequencies of bacterial plant pathogens. Phytopathology 75:505509.

Shaw, P. D., Ping, G., Daly, S. L., Cha, C., Cronan, J. E., Jr., Rinehart, K. L., and Farrand, S. K. 1997. Detecting and characterizing $N$-acyl-homo- 
serine lactone signal molecules by thin-layer chromatography. Proc. Natl. Acad. Sci. U.S.A. 94:6036-6041.

Smadja, B., Latour, X., Faure, D., Chevalier, S., Dessaux, Y., and Orange, N. 2004. Involvement of $N$-acylhomoserine lactones throughout plant infection by Erwinia carotovora subsp. atroseptica (Pectobacterium atrosepticum). Mol. Plant-Microbe Interact. 17:1269-1278.

Toth, I. K., Newton, J. A., Hyman, L. J., Lees, A. K., Daykin, M., Ortori, C., Williams, P., and Fray, R. G. 2004. Potato plants genetically modified to produce $\mathrm{N}$-acylhomoserine lactones increase susceptibility to soft rot erwiniae. Mol. Plant-Microbe Interact. 17:880-887.

Von Bodman, S. B., Bauer, W. D., and Coplin, D. L. 2003. Quorum sensing in plant-pathogenic bacteria. Annu. Rev. Phytopathol. 41:455-482.

Whitehead, N. A., Barnard, A. M., Slater, H., Simpson, N. J., and Salmond, G. P. 2001. Quorum-sensing in gram-negative bacteria. FEMS (Fed. Eur. Microbiol. Soc.) Microbiol. Rev. 25:365-404.
Willis, D. K., Holmstadt, J. J., and Kinscherf, T. G. 2001. Genetic evidence that loss of virulence associated with gacS or gacA mutations in Pseudomonas syringae $\mathrm{B} 728$ a does not result from effects on alginate production. Appl. Environ. Microbiol. 67:1400-1403.

Willis, D. K., Hrabak, E. M., Rich, J. J., Barta, T. M., Lindow, S. E., and Panopoulos, N. J. 1990. Isolation and characterization of a Pseudomonas syringae pv. syringae mutant deficient in lesion formation on bean. Mol. Plant-Microbe Interact. 3:149-156.

Wilson, M., Hirano, S. S., and Lindow, S. E. 1999. Location and survival of leaf-associated bacteria in relation to pathogenicity and potential for growth within the leaf. Appl. Environ. Microbiol. 65:1435-1443.

Yu, J., Peñaloza-Vázquez, A., Chakrabarty, A. M., and Bender, C. L. 1999. Involvement of the exopolysaccharide alginate in the virulence and epiphytic fitness of Pseudomonas syringae pv. syringae. Mol. Microbiol. 33:712-720. 